\title{
Self - infilicted lesions in children - indicator of intra familial
} abuse

${ }^{1}$ Bistrita-Nasaud County Forensic Division

${ }^{2}$ Psychology Department, "Danubius" University of Communication and International Relations

${ }^{3}$ Faculty of Medicine, University "Ovidius" of Constanta

\begin{abstract}
Abstract: Self - inflicted lesions refers to a behavioural disorder with a complex ethiology. The occurrence of these cases in minors seems to be on the increase in last years, as well as minors abuse. On the assumption that there is a possible relation between minors abuse and this behavioural disorder, it has been evaluated comparatively the frequency with which it occurs among the minors examined in the forensic practice following reported abuse and the frequency with which it appears among the general population, sampled from the pupils in the final year of a high school in Bistrita.
\end{abstract}

Keywords: child abuse, self-infected lesions, nonsuicidal self-injury.

\section{Codrin Rebeleanu}

Bistrita-Nasaud County Forensic Division

Garii Street, No. 11, Bistrita, Romania

email : rebeleanuc@yahoo.com

phone: +40744374899

\section{Introduction}

It is in during the teen years that aptitudes outline, intelligence diversifies and the development of future plans begins, moreover, self-identification within society is taking place. All along this period, the minor is sensitive to the influences and pressures exerted by the environment, thus being prone to developing deviant behaviour, also called 'behavioural syndrome' by some authors [1]. Among the negative environment factors that can have an impact on the developing personality we can count intra familial aggression, a worldwide negative phenomena on a worrying rise in many countries of the world. [2].

Self- inflicting traumatic lesions without a suicidal intent seems also to be on the rise in the Romanian contemporary society. This behavioural disorder has been defined as non suicidal self injury [3] (NSSI -nonsuicidalself injury), for which the suggested diagnostic criteria are the following: 
- It has been more than 5 times during the last year that the individual has self inflicted body lesions

- The purpose in of lesion inflicting was to find relief from a psychological state, to solve an interpersonal problem or to acquire psychological well-being

- The production of lesion is associated to at least one of the following situations: difficulties in interpersonal relationing or negative psychological states such as: depression, anxiety, fury etc, concentration on trying to modify one's behaviour or frequent thinking of self - inflicting lesions

- The behaviour is not socially induced (such as body-piercing or tattooing) nor is it part of a relifious ritual

- The behaviour is not a follow-up of some psychotic episode, substance intoxication and can't be explained by another psychiatric disorder.

Romanian specialised literature treats mostly self- inflicting lesions in adults, which has been more frequently noted within the concentrationary environment [4], and mostly known as 'self mutilaton', while the evaluation of this issue in minors has not been made. Some authors use the term of 'parasuicide', defined as wish for self-harm aimed at emotional blackmailing or getting revenge on the people that are emotionally significant for the individual [5]. There are numerous studies on the minors that focus on child abuse under its different forms (physical, psychological, sexual, abandon and neglect) [6]. Intra familial abuse in children is a particularly widespread phenomenon, $18.4 \%$ of the Romanian children are physically abused, and $0.1 \%$ are sexually abused [7]. Out of these a smaller percentage are brought to attention of authorities and benefit from forensic examination followed by appropriate protective measures. The question has been raised as to whether deviant behaviour such as lesion self-inflicting might be an alarm signal indicating a form of intra familial abuse.

\section{Material and method}

On analysing the forensic documents in the archive of the Bistrita Forensic Service, it has been evaluated the number of children examined for familial abuse in the years 2013, 2014 and 2015 who also presented marks of earlier self-inflicted lesions at various stages of healing. The comparison has been made with a lot of 208 students in the first and second grade of 'Sanity' - a nursing post- high school in Bacau- who were handed in anonymous surveys containing such items as:

'Have you ever self - harmed (by cutting yourself, stinging, burning etc)? YES/NO

'Have you ever seriously thought of selfharming? YES/ NO

The same questions were asked to the minors aged over 12 that got traumatologic and genital examination in 2013, 2014 and 2015 at the Bistrita Forensic Service due to prior intrafamilial abuse. The answers were corroborated with the objective exams of the individuals. It was set the above age threshold as there were noticed no self-inflicted lesions in children younger than 12 examined at that point.

The results from the control group were statistically processed and compared with the results from the abused minors evaluated.

In the statistical analysis of the data the premise was that the control group was a representative sample for the study of the analysed problem.

\section{Results}

The control group consisted of 208 students from the 'Sanity' Post High School in Bacau. 207 of them answered negatively to the first question and 206 answered negatively to the second one.

Throughout the 3 years that made the object of the analysis, 138 minors over 12 were examined at the Bistrita Forensic Service. Some of them had 
been referred by the General Directorate for Social Care and Child Welfare Bistrița-Năsăud, some were presented at the initiative of their relatives (mother, grandparents), and in very few cases it was the minor concerned who had the initiative of getting a forensic examination following a physical abuse. Out of the 138 minors examined, in 19 cases there were recorded earlier self-harming lesions, confirmed by the anamnesis. The minors also received the two questions of the survey. The answer to the first question was affirmative in 24 minors (thus, there were 5 more than those presenting visible scars), and for the second question the answer was affirmative in 31 cases.

It has been recorded a significant difference between the two groups that were evaluated from the point of view of the percentage of minors who had self- harmed: $0.48 \%$ in the control group, $13.77 \%$ abused minors presenting self-inflicted lesions respectively, and a total of $17.39 \%$ who admitted to having self-harmed.

As far as the percentage of minors admitting to have had serious thoughts of self-harming, the size of the discrepancy between the two groups is the same: 0.96 in the control group versus $22.46 \%$ in the abused minors - see Table I.

Table I The respondents that admitted self-harming and those that admitted thinking of self-harming in the control group and in the abused minors group

\begin{tabular}{|l|c|c|c|}
\hline & Total & $\begin{array}{l}\text { Admit } \\
\text { self-harming }\end{array}$ & $\begin{array}{c}\text { Admit thinking } \\
\text { of self-harming }\end{array}$ \\
\hline $\begin{array}{l}\text { Control } \\
\text { group }\end{array}$ & 208 & $1(0.48 \%)$ & $2(0.96 \%)$ \\
\hline $\begin{array}{l}\text { Abused } \\
\text { minors } \\
\text { group }\end{array}$ & 138 & $24(17.39 \%)$ & $31(22.46 \%)$ \\
\hline
\end{tabular}

It has been recorded that, in the group of abused minors who admitted having thought of self-harming, the number of those who enacted it reveals a majority, namely 24 out of 31 , that is $77.42 \%$.

Case study:

We present the case of a 14 years old female patient presented at the forensic examination by the General Directorate for Social Care and Child
Welfare. The teenager, from the rural environment, had been chronically abused by her father, with whom had been entertaining sexual intercourse under a death threat in case she opposed or told somebody else. The decision to come forward had been determined by her mother's coming home from abroad, and confessing to her. On genital examination it was recorded 'earlier deflowering, whose date cannot be specified'. The objective forensic examination revealed numerous lesions specific to self-injury: 'on the $1 / 2$ distal anterior side of the left forearm, 8 whitish scars, parallel with each other, horizontal, with a length of 4/0.3-6/0.5 $\mathrm{cm}$. On the anterior side of the left palm, an elevated whitish scar, of circular shape, with a diametre of 0.6 $\mathrm{cm}$ '. It was concluded that the lesions might have been produced by means of a cutting object and an incandescent object (e.g. a cigarette), and that they were very likely to have been self-inflicted. The brief psychological, examination recorded good spacetime orientation, normal and coherent speech, normal ideation, train of thought with no bradipsychic or tachipsychic disorders. She admitted having modest school results, mostly because of the absenteeism, but mentioning that school results improve when she goes to school. Good sense of humour. Open look, fatalist attitude ('It so happened...'), and, as far as her father is concerned, she tries to avoid the issue. The only comment is 'He didn't have the right to do what he did'. Minor's attitude towards the self-inflicted injuries was natural, with no drama, slightly embarrassed: 'I did those when I was younger ... last year.' The reason given for self-inflicting the lesions doesn't seem too convincing to her anymore. "I cut myself with a razor blade, as I thought I would feel better afterwards, but it did not happen.' She doesn't think she will inflict herself such injuries in the future.

\section{Discussions}

Within the general population, self-harming behaviour is rare, while in the abused minors this kind of behaviour is more common. Even though not all 
abused minors have self-harming thoughts, 20 times more of them than those in the control group admitted to having had such intentions.

Most minors admitting to have seriously thought of self- harming enacted it; there is a possibility that the number of those having such thoughts at a certain point is larger in the population, but to have blocked them, in a self-defense protecting mechanism.

\section{Conclusions}

1. Non suicidal self-harming acts prevail significantly in the abused minors rather than in the general population.

2. There is no evidence to corroborate directly the activity of self-harming with the intra familial abuse, though the minors with a self- harming history might be considered as possible abuse victims.

\section{References}

1. Racasanu, R., Marineanu, C. \& Stoian S. (1997). Considerente clinic-psihologice in investigarea si expertiza medico-legala a adolescentilor cu tulburari de comportament. Romanian Jurnal of Legal Medicine. 5(4), 369-374.

2. Belis, V. \& Curca, C. (1997). Vatamarea corporala si abuzul sexual intrafamilial la minori, Romanian Jurnal of Legal Medicine. 5(2), 160166.

3. American Psychiatric Association. (2013). Diagnostic and Statistical Manual of Mental Disorders (DSM-5): American Psychiatric Publishing. (pp. 803)

4. Vartic, M. \& Anitan, S. (2004). Automutilarea in penitenciare, Romanian Jurnal of Legal Medicine. 12(4), 275-284.
5. Buhas, C., Ardelean, H. \& Mihalache, G. (2003). Violenta intrafamiliala ca factor favorizant al suicidului la minori, Romanian Jurnal of Legal Medicine. 11(2), 154-158.

6. Plahteanu, M. (2001). Complexitatea expertizei medico-legale a minorilor maltratati, Romanian Jurnal of Legal Medicine. 9(3), 268-271.

7. Curca, G.C., Buda. O., Capatana. C.\& Marinescu, M. (2008). Study on domestic violence: a legal medicine perspective, Romanian Jurnal of Legal Medicine. 16(3), 226-242. 